\title{
Managing Chronic Pain in Patients With Opioid Dependence
}

\author{
Jane Liebschutz, MD, $M P H^{1, *}$ \\ Donna Beers, $R N^{1}$ \\ Allison Lange, $B A^{1,2}$
}

\author{
Address \\ ${ }^{*}, 1$ Clinical Addiction and Research Unit, Section of General Internal Medicine, \\ Boston Medical Center, Boston University School of Medicine, 801 Massachusetts \\ Avenue, 2nd Floor, Boston, MA 02118, USA \\ Email: Jane.Liebschutz@bmc.org \\ ${ }^{2}$ Duke University School of Medicine, Durham, NC 27707, USA \\ Published online: 1 April 2014 \\ (C) Springer International Publishing AG 2014
}

\begin{abstract}
Keywords Chronic pain - Opioid dependence - Substance use disorders - Treatment - Addiction - Multimodal interventions - Cognitive behavioral therapies - Substance abuse treatment groups · Physical therapy • Yoga • Exercise · Obesity • Dieting • Analgesic • Medication
\end{abstract}

\section{Opinion statement}

Chronic pain may last for months to years, and is often heightened by co-morbid opioid dependence; setting realistic expectations for both patient and physician is therefore a key step in formulating treatment plans. Chronic pain is influenced by psychological, social and environmental factors in addition to somatic pathology, thus treatment needs to encompass more than just analgesia. The specific treatments should address contributors to and sequelae of chronic pain and addiction (e.g., social isolation, physical disability, depression, anxiety, obesity, financial stress, housing instability) and include multimodal interventions: psychosocial engagement, physical mobility and conditioning, weight loss, substance use treatment, and medications. Psychosocial treatments include evidence-based cognitive behavioral therapies, substance abuse treatment groups, 12-step programs and other social activities. Physical mobility and conditioning can be accomplished with physical therapy, yoga, or other exercise programs, and are essential to avoid loss of function and a negative functional spiral. In the setting of obesity, diet in combination with exercise can decrease pain and improve function. Substance abuse treatment is essential for patients with comorbid pain and opioid dependence. Opioid replacement therapies may have some added analgesic benefit. Medication can help decrease the pain level and alleviate some of the complicating conditions but is unlikely to be effective when used in isolation. Opioid analgesics are generally not recommended in cases of patients with opioid dependence because of mixed evidence for efficacy and high risk. 


\section{Introduction}

"Pain is inevitable; Suffering is optional." (M. Kathleen Casey).

Pain is a subjective multi-dimensional experience that is influenced by physiological stimuli and the emotional, cultural, environmental and social climate surrounding an individual. Chronic pain, usually defined as lasting 12 weeks or longer, is associated with increased psychological distress, decreased mobility, obesity, decreased physical function, social isolation, financial loss, and development of chronic disability [1]. Individuals with opioid dependence may have increased vulnerabilities that influence their experience of pain, including lowered pain thresholds [2, 3], increased social stress, psychological symptoms (depression, anxiety), financial strain, and decreased coping skills. More than one-third of patients on methadone maintenance therapy have chronic severe pain $[4,5]$. In some cases, patients developed opioid addiction after being given opioid medication for the treatment of acute or chronic pain [6].

Since chronic pain lasts for months to years [7], a primary goal of treatment is to manage the pain, rather than eliminate pain altogether. This is true in patients with and without addictive diseases, but is particularly important to establish in patients with addiction. Pain is associated with increased odds of opioid misuse in opioid dependent persons [8]. Managing expectations of both clinician and patient is a mainstay of treatment. A second principle is to address the individual symptoms contributing to and resulting from chronic pain and those of importance to the patient. Lastly, self-management of pain symptoms and sequelae should be integrated into all aspects of pain treatment. Very little evidence exists specifically for treating pain in patients with addiction of any type, but principles of pain treatment in the general population are applicable to patients with opioid dependence.

The five pillars of treatment include:

1) Improving psychosocial engagement. Cognitive behavioral therapy as well as other therapies may be helpful for pain [9, 10] but has not been proven to be helpful in opioid dependence [11-13]. Mindfulness- based therapies have been studied for pain management but have shown little efficacy to date $[14,15]$. De- veloping a specific plan for socialization, whether it be participation in a regular substance abuse treatment group, 12-step program or other activity (perhaps with family or friends), is key to keeping the patient engaged. In particular, with pain and disability, finding a way to feel useful and engaged is essential to recovery from chronic pain. Case management or social work referral may help patients identify potential aid for financial or housing stress.

2) Physical mobility and function. A variety of methods can be used for patients to improve and maintain physical function. Increasing activity can improve mood [16, 17], increase weight loss [18], prevent deconditioning and improve pain related disability [19]. Physical therapy and other modalities (yoga) improve pain outcomes [20-28].

3) Weight loss in persons with obesity. A combination of diet and exercise for weight loss can improve pain symptoms and function [29].

4) Engagement with substance use treatment and/or relapse prevention. To treat pain optimally, patients also need to focus on their substance use, including taking accountability for their use. In the experience of the authors, some patients with substance use disorders may focus so much on the pain that they avoid doing the cognitive and emotional work required to recover from substance use problems. Full commitment to substance use disorder treatment is central to success of managing pain.

5) Medications. Medications can be used to both decrease the pain sensation but also to treat the other symptoms that occur with chronic pain. Medications from different classes may be synergistic to relieve symptoms. Opioid medications are not recommended to treat chronic pain in patients with opioid dependence. The exception would be a patient with terminal cancer, for whom it would be appropriate. Opioid agonist treatment for addiction may have benefits for chronic pain [30•]. Opioids are appropriate for acute pain in an inpatient medical setting. 


\section{Treatment}

\section{Diet and lifestyle}

- Weight loss has been shown to decrease disability from osteoarthritis in obese patients in combining results from several trials together [31]. An individual study found that it was the combination of exercise plus diet together that improved function and decreased pain in osteoarthritis, whereas diet alone was not effective [32]. Both strength training and aerobic walking have been shown to improve pain and function in osteoarthritis, Class I [33].

- Self-management is a process by which patients with a chronic illness or disability learn to effectively care for themselves via training, intervention, or skills acquisition. This process has been shown to improve pain, distress, and mood in patients with chronic pain in small randomized trials. Self-management using CBT has been shown to be effective in a randomized trial of 141 adults, improving pain, distress, disability, and mood at one month follow up, Class II [34]. Benefits of self-management in patients with chronic neck pain were sustained over a two year follow up period [35].

\section{Pharmacologic treatment}

- The treatment aims of pharmacological therapy include reduction of pain, but also reduction of symptoms that accompany chronic pain, such as depression, anxiety, sleep, and muscle spasm. Most medications were developed and tested in populations without active addiction problems, however. Effectiveness in patients with addiction is unknown, except where noted.

- A multimodal medication regimen combines medications with different underlying mechanisms. Additive analgesia may occur and this approach allows lower doses of each of the drugs in the treatment plan, which lowers the potential for each to produce adverse effects [36]. Further, multimodal analgesia may result in comparable or greater pain relief than can be achieved with any single analgesic [37]. It may also be more effective at treating the co-occurring symptoms that accompany chronic pain and addiction.

- Patients with substance dependence who are in recovery through an abstinence-based program (e.g., Alcoholics Anonymous; Narcotics Anonymous) may be reluctant to take psychoactive medications, although these programs encourage their members to take medications that have been legitimately prescribed by their physician.

WHO's pain relief ladder (WHO; 1986)

- The World Health Organization Pain Relief ladder [38] was developed and promulgated internationally as a cohesive view toward 
treating cancer pain. It has been also adapted for non-cancer chronic pain, but prescribers should cautiously approach its applicability in patients with co-occurring addiction and pain because opioids are a mainstay of treating severe pain. In general, opioids are not recommended to treat chronic pain in patients with addiction, even if they are in recovery.

- The analgesic ladder focuses on selecting analgesics on the basis of the intensity of the pain using analgesics from each of the analgesic groups and, to some extent, building on previously effective analgesics.

- Step 1: Simple analgesics (acetaminophen, NSAIDs)

- Step 2: Weak opioids

- Step 3: Strong opioids

- Adjuvants (anti-seizure medications, muscle relaxants, TCAs, SNRIs, SSRIs). These may be added at any of the above 3 steps.

\section{Simple analgesics}

Acetaminophen has been shown to be better than placebo in patients with chronic pain due to osteoarthritis of the knee with respect to pain control, but not superior to non-steroidal anti-inflammatory medicine (NSAIDs), Class I [39]. However, acetaminophen can be considered first-line for chronic pain because it has a better side effect profile than NSAIDs, Class I [40].

Acetaminophen

Standard dosage $650 \mathrm{mg}$ Q6 hours (Max $2000 \mathrm{mg}$ if cirrhosis or $\geq 3$ alcoholic drinks/day)

Contraindications Patients with liver impairment and those with daily, regular alcohol intake

Main drug interactions Anticonvulsants, barbiturates, carbamazepine may increase the metabolism of acetaminophen; isoniazid, prilocaine. Acetaminophen increases the effects of warfarin with doses $>1.5-2 \mathrm{~g} /$ day. Acute excessive intake of alcohol can lead to increased risk of acetaminophen hepatotoxicity.

Main side effects Occasional skin rash and other allergic reactions. Acute overdose can cause fatal hepatic injury.

Special points Well tolerated. Can be combined with other analgesics. Effective analgesicantipyretic agent, but its anti-inflammatory activity is weak. When used as part of multimodal analgesia, can reduce the amount of opioids needed to control pain.

Cost Low cost

\section{Non-steroidal anti-inflammatory (NSAID)}

This category of medications includes a number of over-the-counter and prescription options. Doses suggested are prescription level. This list is a sampling of widely used options. For all NSAIDs, urticaria, or allergic-type reactions following aspirin or other NSAIDS is a contraindication to use. In a systematic review of 65 RCTs including 11,237 patients, strong evidence was found to support the efficacy of NSAIDs and COX-2 inhibitors for acute and 
chronic low back pain, Class I [41]. All NSAIDs were found to have similar efficacy.

Naproxen

Standard dosage

Contraindications

Main drug interactions

Main side effects

Special points

Cost

Ibuprofen

500 mg Q12 hours or 500 Q AM plus 250 BID (Max 1000 mg/24 hours)

Full-dose naproxen is not recommended in older adults because of its long half-life.

Avoid combining NSAIDS. May interact with drugs prescribed for cardiac disease including anti-hypertensive, anti-platelet and anti-coagulant medications.

GI toxicity, renal toxicity, platelet dysfunction.

First line NSAID.

Low cost

$600 \mathrm{mg}$ every 6 hours (Max $2400 \mathrm{mg} / 24$ hours)

ACE-inhibitors, aspirin, lithium, warfarin.

GI toxicity, renal toxicity, platelet dysfunction.

Second line NSAID. Ibuprofen can interfere with the cardioprotective effect of aspirin, so it should be taken 30 minutes to 2 hours after aspirin intake or at least 8 hours before. Pregnancy Category C.

Cost Low cost

Piroxicam

Standard dosage

Contraindications

Main drug interactions

Main side effects

Special points

Cost
10 mg once daily

Avoid full dose in elderly due to its long half-life and risk of GI toxicity. ACE-Inhibitors, MAOIs, aspirin, warfarin.

High risk of GI toxicity, renal toxicity, platelet dysfunction.

Second line NSAID. Pregnancy Category C.

Moderate cost

Diclofenac

Standard dosage

Main drug interactions

Main side effects

Special points

Cost

Indomethacin
18 or 35 mg orally 3 times daily

Concomitant use with other NSAIDS may result in enhanced gastrointestinal adverse effects (peptic ulcers, gastrointestinal bleeding and/or perforation).

Increased liver function tests.

Second line NSAID. Pregnancy category C.

High cost
Standard dosage

Main drug interactions

Main side effects
Maximum recommended is 25-50 mg, 2-3 times per day (oral or rectal dose) Concurrent use of other NSAIDs may result in enhanced gastrointestinal adverse effects (peptic ulcers, gastrointestinal bleeding and/or perforation). Dizziness, headache, GI toxicity, increased liver enzymes, renal toxicity. 
Special points Use lowest effective dose for shortest possible duration - this is to be used in short term only.

Cost Low cost

\section{COX-2 inhibitors}

This subset of NSAID category of medications have less gastrointestinal side effects. Some formulations have been found to increase risk for cardiovascular disease and have been removed from the market. Urticaria or allergictype reaction to aspirin or other NSAIDS is a contraindication to use. In a randomized controlled trial of 446 patients with chronic low back pain, a COX-2 inhibitor was found to be comparable to NSAIDs for pain relief, Class II [42]. In a systematic review of patients with chronic low back pain, two randomized trials compared COX-2 inhibitors with traditional NSAIDs, and no statistically significant difference was found between the two treatments, Class I [43].

Nabumetone

\begin{aligned} \hline Standard dosage & Arthritis $1000-2000$ mg daily in two doses. \\ Contraindications & Allergy or hypersensitivity to aspirin or NSAIDs. \\ Main side effects & Edema, pruritus, rash, constipation, diarrhea, headache, tinnitus. \\ Special points & $\begin{array}{l}\text { The drug is best taken with food or milk. Patient should not drink alcohol } \\ \text { while taking this drug. }\end{array} \\$ Cost & Moderate cost \end{aligned}

Standard dosage 200-400 mg daily in two doses.

Contraindications Asthma, pruritis, rhinorrhea, or other reaction after aspirin or other NSAID. Up to $21 \%$ of patients with a hypersensitivity to NSAIDs also have a hypersensitivity to COX-2 inhibitors [44].

Main drug interactions Concurrent use of NSAIDs may result in enhanced gastrointestinal toxicity.

Main side effects Hypertension, diarrhea, headache.

Special points Instruct patients on higher doses (400 mg twice daily) to take drug with food. Lower doses may be taken with or without food. Tell patient to avoid drinking alcohol and smoking, as this may increase risk for gastrointestinal bleeding.

Cost Moderate cost

\section{Muscle relaxants}

Of note, carisoprodol (Soma) is a muscle relaxant that is metabolized to a barbiturate and should not be prescribed for patients with opioid dependence. Cyclobenzaprine is the best studied muscle relaxant. A meta-analysis of five RCTs showed that cyclobenzaprine had efficacy for treating pain due to fibromyalgia [45], and later Kroenke et al. found that 21 RCTs show that cyclobenzaprine is effective for pain relief in patients with fibro- 
Cyclobenzaprine: (Flexeril)

myalgia [40]. A recent randomized trial of 36 patients showed that low-dose cyclobenzaprine improved pain associated with FM, Class II [46].

Standard dosage

Immediate release: $5 \mathrm{mg}$ TID, may increase to $10 \mathrm{mg}$ TID; extended release: $15 \mathrm{mg}$ PO daily.

Contraindications Cardiac conduction disturbances, CHF, hypersensitivity, hyperthyroidism, MI (or acute recovery period).

Main drug interactions MAOIs, TCAs, bupropion phenothiazine, clonidine.

Main side effects Dizziness, sedation, dry mouth, orthostatic hypotension.

Special points Generally well-tolerated but have sedative effects that may be additive to other centrally-acting drugs, including opioids. Muscle relaxants are not recommended in older adults as this age group has increased sensitivity to the anticholinergic and sedating effects of the drugs, and the muscle relaxant effect may contribute to falls [47].

Cost Low cost

\section{Anti-seizure medications}

Anti-seizure medications, in particular gabapentin and pregabalin, are FDA approved to treat neuropathic pain. A Cochrane Review in 2013 found that gabapentin and pregabalin were supported by second tier evidence for the treatment of diabetic neuropathy and post-herpetic neuralgia, Class I [48]. Evidence also supported the use of pregabalin in fibromyalgia for pain [48].

Gabapentin: (Neurontin)

$\begin{aligned} \text { Standard dosage } & \text { Titrate up to } 900-1200 \mathrm{mg} \text { TID } \\ \text { Contraindications } & \text { Kidney disease, depression, pregnancy. } \\ \text { Main drug interactions } & \text { Antacids. } \\ \text { Main side effects } & \text { Sedation, dizziness, unsteadiness, and nausea. } \\ \text { Special points } & \begin{array}{l}\text { Adverse effects usually lessen with time. Reports of abuse exist for gabapentin } \\ \text { at high doses. }\end{array} \\ \text { Cost } & \text { Moderate cost }\end{aligned}$

Pregabalin:(Lyrica)

Standard dosage

Contraindications

Main drug interactions

Main side effects

Special points
300-450 mg daily in two doses.

Caution in elderly, depressed, renal impairment, heavy alcohol consumption.

Pioglitazone (Actos) and rosiglitazone (Avandia).

Sedation, dizziness, unsteadiness, and nausea.

Adverse effects usually lessen with time. Approved for treatment of fibromyalgia. Should be considered the first-line drug for the treatment of post-herpetic neuralgia and other neuropathies unless a co-morbid depression suggests that a tricyclic antidepressant should be tried first [49, 50]. 


\section{Cost High Cost}

\section{Tricyclic antidepressants (TCAs)}

TCAs have been shown to be more effective in fibromyalgia than other anti-depressants as well as other treatment options [51, 52]. In addition to the two wellstudied TCAs listed below, a number of other TCAs are likely to be equally effective.

Amitriptyline: (Elavil)

\begin{tabular}{|c|c|}
\hline Standard dosage & $\begin{array}{l}\text { Start at } 10-25 \mathrm{mg} \text { at bedtime; titrate to } 100 \mathrm{mg} \text { (max } 50 \mathrm{mg} \text { if taking an } \\
\text { SSRI/SNRI). }\end{array}$ \\
\hline Contraindications & TCA allergies. \\
\hline Main drug interactions & $\begin{array}{l}\text { MAOIs, St. John's Wort, clonidine. Use with caution with other medications } \\
\text { that cause QTc prolongation. }\end{array}$ \\
\hline Main side effects & Sedation, orthostatic hypotension, urinary retention, and dry mouth. \\
\hline Special points & Avoid in older adults. \\
\hline Cost & Low cost \\
\hline \multicolumn{2}{|l|}{ Nortriptyline:(Pamelor) } \\
\hline Standard dosage & Start at $10-25 \mathrm{mg}$, titrate to $100 \mathrm{mg}$ (max $50 \mathrm{mg}$ if taking an SSRI/SNRI) \\
\hline Contraindications & TCA allergies. \\
\hline Main drug interactions & $\begin{array}{l}\text { Alcohol can increase side effects. Use with caution with other medications } \\
\text { that cause QTc prolongation. }\end{array}$ \\
\hline Main side effects & Sedation, orthostatic hypotension, and dry mouth. \\
\hline Special points & $\begin{array}{l}\text { Try at least } 2 \text { TCAs but avoid in older adults ( } 65+\text { years). It has less hypo- } \\
\text { tension than Amitriptyline. }\end{array}$ \\
\hline Cost & Low cost \\
\hline
\end{tabular}

\section{Selective serotonin reuptake inhibitors (SSRIs)}

Fluoxetine, fluvoxamine, paroxetine, sertraline, citalopram, escitalopram

SSRIs have been used for chronic pain, although have less efficacy than TCAs for fibromyalgia. The beneficial effect on chronic pain may be more on the co-occurring symptoms, in particular depression, associated with chronic pain rather than the pain itself. In a trial of 12 weeks of treatment with antidepressant medication $(n=123)$ or usual care $(\mathrm{n}=127)$, at 12 months patients receiving the intervention had greater reduction in depression and pain, Class I [53].

Standard dosage Dosing varies based on the SSRI.

Contraindications

Main drug interactions

Hypersensitivity to sertraline, fluoxetine, paroxetine, or citalopram.

Main side effects

Disulfiram, MAOI within 14 days, pimozide.

Sexual dysfunction, drowsiness, weight gain, insomnia, anxiety, dizziness, headache, dry mouth, blurry vision, nausea, rash, tremor, constipation. 
Cost Moderate cost (variable, depending on which medication)

\section{Serotonin norepinephrine reuptake inhibitors (SNRIs)}

This class of medications treats both mood and a variety of other disorders - fibromyalgia, neuropathic pain, and menstrual syndromes. Duloxetine

was found to be effective for treating pain due to fibromyalgia in a recent Cochrane review, Class I [54].

Venlafaxine: (Effexor)

\begin{tabular}{|c|c|}
\hline Standard dosage & Start at $37.5 \mathrm{mg}$ and titrate up to effective dose, with max at $225 \mathrm{mg}$ daily \\
\hline Contraindications & Glaucoma, heart disease, HTN, mania, seizure disorders. \\
\hline Main drug interactions & MAOIs, SSRIs St John's Wort. \\
\hline Main side effects & Dizziness, drowsiness, nausea and vomiting, dry mouth. \\
\hline Special points & $\begin{array}{l}\text { Better adverse event profile than TCAs [55]. Use cautiously in patients with } \\
\text { high CV risk. Should not stop abruptly. Can cause dose-related hypertension, } \\
\text { and, if appropriate, blood pressure (BP) monitoring should be done } \\
\text { during initiation of treatment. }\end{array}$ \\
\hline 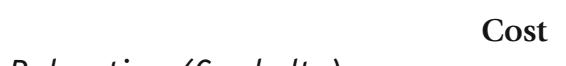 & Low cost (generic available) \\
\hline \multicolumn{2}{|l|}{ Duloxetine (Cymbalta) } \\
\hline Standard dosage & Titrate up to $60 \mathrm{mg}$ daily \\
\hline Contraindications & $\begin{array}{l}\text { An increase in hepatotoxicity has been linked to the use of duloxetine in } \\
\text { individuals with pre-existing liver disease, suggesting that the drug may ag- } \\
\text { gravate the disease. }\end{array}$ \\
\hline Main drug interactions & MAOIs, selegiline, tranylcypromine. \\
\hline Main side effects & Dizziness, fatigue, and dry mouth. \\
\hline Special points & $\begin{array}{l}\text { FDA-approved for fibromyalgia and diabetic neuropathy. Side effects can } \\
\text { be reduced by starting at } 30 \mathrm{mg} \text { daily for } 1 \text { week and then increasing to } \\
60 \mathrm{mg} \text { daily. Should not be stopped abruptly. Numerous trials have } \\
\text { shown efficacy in decreasing pain due to osteoarthritis }[56,57] \text {. Better } \\
\text { adverse event profile than TCAs [55]. }\end{array}$ \\
\hline Cost & High cost \\
\hline
\end{tabular}

\section{Dual mechanism opioids}

These medications have both mu-opioid agonist and nor-epinephrine (+/-) serotonin reuptake inhibitor properties. This may improve inhibitory processes in the mid-brain to decrease pain signals. Both have abuse and addiction potential.

\section{Tramadol}

Standard dosage

Contraindications
Immediate release: 50-100 mg every 4-6 hours. Can start with $25 \mathrm{mg}$ and titrate up to full doses, to a maximum of $400 \mathrm{mg}$ per day.

Hypercapnia, acute or severe bronchial asthma, respiratory depression, hypersensitivity to opioids. 
Main drug interactions

Main side effects

Special points

Cost Low cost

Tapentadol

Acute intoxication with alcohol, hypnotics, narcotics, centrally acting analgesics, or psychotropic drugs (may worsen CNS and respiratory depression).

Flushing, pruritis, constipation, nausea, vomiting, dizziness, headache, insomnia, somnolence. Rarely, seizure, dyspnea, pancreatitis.

Patients should be tapered if they are on tramadol chronically.

Standard dosage Immediate release: 50-100 mg every 4-6 hours as needed. Maximum dose of $600 \mathrm{mg}$ per day. Extended release: $50 \mathrm{mg}$ twice daily. Titrate up by $50 \mathrm{mg}$ every three days, up to therapeutic range of $100-250 \mathrm{mg}$ PO twice daily. Maximum dose of $500 \mathrm{mg} /$ day.

Contraindications Hypercapnia, bronchial asthma, hypersensitivity to tapentadol, GI obstruction, respiratory depression.

Main drug interactions MAOIs, sedatives.

Main side effects Constipation, nausea, vomiting, dizziness, Headache, somnolence, hypotension, left bundle branch block, anaphylaxis, seizure, respiratory depression.

Special points Seizure potential

Cost Moderate cost

\section{Opioids}

Although opioids are a common treatment for chronic pain, they are not recommended for patients with active addiction of any type. They can be cautiously recommended for patients in stable recovery, although even then have to be closely monitored. Use of opioids may become problematic in patients with prior addiction. High quality studies on use of opioids for chronic non-cancer pain are not available, and most available trials of opioids for chronic pain are limited by the exclusion of patients with addiction, sponsorship by pharmaceutical industry, small sample sizes, and short duration. A Cochrane review combining the largest trials with 8-13 month follow up found that only $44 \%$ of patients treated with opioids experienced a $50 \%$ reduction in pain [58]. In certain patients, the underlying pain condition may warrant use of opioids, in which case, they should be under the care of someone with both addiction and pain expertise who has the ability to do close monitoring with pills counts and urine drug testing.

Two opioids used in the treatment of opioid dependence have potential analgesic properties. A study of patients with addiction on chronic opioid therapy who were randomized to low dose methadone or buprenorphine/ naloxone found that these medications produced moderate analgesia [30•].

For chronic pain treatment: methadone should be started at very low doses and increased slowly over weeks. Since the analgesic half-life is 6-8 hours, it should be given 3-4 times daily. It can be started at 2.5-5 mg 3-4 times per day, with increases done at weekly intervals. For chronic pain, 30-60 mg total daily dose is a typical range.

For opioid dependence: methadone should be prescribed by programs and providers with federal licensure to treat opioid dependence with methadone. 
Main drug interactions

\author{
Main side effects \\ Special points
}

It should not be initiated for this purpose without enrollment in such a program. For opioid dependence, methadone is started at a dose of 20$30 \mathrm{mg} /$ day, with a maximum dose of $30 \mathrm{mg}$ [59, 60]. An additional $10 \mathrm{mg}$ can be given on the first day if withdrawal symptoms persist hours later. If the initial dose of methadone is too high, patients may experience respiratory depression, urinary retention, edema, and abdominal distension. After the first day, the dose is then increased at 5$10 \mathrm{mg}$ increments daily until $60-80 \mathrm{mg} /$ day is reached. Dose increases after $80 \mathrm{mg} /$ day should proceed slowly based on the individual patient's cravings and withdrawal symptoms. Most patients are stable on doses 80-120 mg/day [59].

Phenytoin, phenobarbital, carbamazepine, rifamycins, benzodiazepines. Concomitant use with MAOI's can induce serotonin syndrome.

Constipation, sedation, potential QTC prolongation.

Methadone serum half-life ranges from 20-100 hours, and is dosed every 24 hours for opioid replacement therapy. The analgesic effects of methadone are much shorter ( $6-8$ hours) and it is given more frequently for pain relief. The peak respiratory depression due to methadone occurs at 12-14 hours after the dose, and lasts longer than the analgesic effects, which contributes to the risk of overdose [60]. Respiratory depression has been implicated as the cause of death in most methadone-related deaths [60]. Even if the patient has a history of opioid tolerance, it should be started at low doses and increased slowly. If the patient is already taking other opioids, those medications can be tapered while the methadone is being titrated up. It can also cause QT prolongation, particularly at higher doses and when combined with other medications with QT prolongation effects. No neurotoxic metabolites. Chronic low-dose methadone may be safe for pain and have the side benefit of suppressing opioid cravings $[30 \bullet]$.

Cost Low cost

\section{Partial opioid agonists}

\section{Buprenorphine}

Standard dosage

Contraindications

Main drug interactions

Main side effects

Special points
8-16 mg sublingual daily for opioid agonist treatment for opioid dependence, but doses may vary in individual circumstances.

Concurrent use of other opioids. Attaches tightly to mu receptor, limiting the ability of other opioids to act.

CNS depressants, azole antifungals, macrolide antibiotics, HIV antivirals, and protease inhibitors.

Taste aversion, sedation in opioid naïve individuals.

Has a ceiling effect at the mu receptor. Respiratory depression not easily reversed with naloxone. It has some analgesic properties, and preliminary data suggests it can be used to treat pain (off-label) and to concomitantly treat opioid dependence [30•]. Because the analgesic effects are shorter than the serum half-life, analgesic dosing should be every 6 hours. 


\section{Cost High cost}

\section{Topical medications}

Capsaicin

Topical medications have shown efficacy for decreasing musculoskeletal pain and often have fewer side effects than systemic therapy. Lidocaine has been proven to be effective for chronic pain due to post-herpetic neuralgia [61] and diabetic neuropathy [62], and limited evidence exists for the use of lidocaine with other chronic pain conditions, Class I [62]. Topical capsaicin is useful as an adjunct to other medications for chronic pain patients, Class I [63]. Topical NSAIDs, such as diclofenac, have proven efficacy for osteoarthritis, but not for chronic low back pain [64].

\begin{tabular}{|c|c|}
\hline Standard dosage & 3-4 times per day for arthritis and musculoskeletal pain. \\
\hline Contraindications & Specific contraindications have not been determined. \\
\hline Main drug interactions & None. \\
\hline Main side effects & $\begin{array}{l}\text { Erythema, pain, rash, or pruritis of application site; nausea; nasopharyngitis; } \\
\text { hypertension. }\end{array}$ \\
\hline Special points & $\begin{array}{l}\text { Treatment area may be heat-sensitive, and patient should not apply cream } \\
\text { directly before bathing, swimming, sun bathing, or exercise. }\end{array}$ \\
\hline $\begin{array}{l}\text { Cost } \\
m \text { and patch (Lidoderm }\end{array}$ & Low cost \\
\hline
\end{tabular}

Standard dosage

Contraindications

Main drug interactions

Main side effects

Cost High cost patch, low cost cream/gel

BenGay (Camphor $4 \%$, Menthol $10 \%$, Methylsalicylate $30 \%$ )

Standard dosage

Contraindications

Main drug interactions

Main side effects

Cost Low cost

Diclofenac (topical)

Apply to affected area 3-4 times daily.

hypersensitivity to Camphor, hypersensitivity to peppermint, menthol, or any other member of the mint family, topical application should not be used on the face or chest of infants or small children or on open skin areas.

No drug interaction data available.

Nausea, vomiting, warmth, headache, confusion, vertigo, delirium, hallucinations, tremors, elevated LDH, contact eczema, contact dermatitis. patches topically at one time, for up to 12 hours within a 24-hour period.

persensitivity to local anesthetics of the amide type.

None for topical lidocaine.

Rare for topical application.

3-4 times per day for arthritis and musculoskeletal pain.

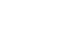


$\begin{aligned} \text { Main side effects } & \text { Local site reaction, blood coagulation disorder [65] } \\ \text { Cost } & \text { High cost }\end{aligned}$

\section{Physical/speech therapy and exercise}

Exercise, including physical therapy, aerobic exercise, and yoga, has been evaluated to treat various chronic pain syndromes, including fibromyalgia and chronic low back pain. Although there is currently no evidence to support the use of exercise in patients with concurrent opioid dependence, the exercise interventions below will likely have a positive effect on these patients.

\section{Physical therapy}

- Exercise has been used to improve pain in patients with chronic low back pain. In a Cochrane review including 43 randomized trials pertaining to chronic low back pain, exercise therapy was found to be slightly effective at decreasing pain and improving function in adults, Class I [20]. A systematic review by Hayden et al. states that healthcare personnel supervision during physiotherapy for chronic low back pain may further improve pain and function, Class I [21].

- Exercise has also been used as a treatment for fibromyalgia. Moderate quality evidence from a Cochrane Review supports aerobic-only exercise training for improving global well-being and physical function for patients with fibromyalgia, Class I [22]. A lack of evidence precludes the evaluation of the benefits of strength-only and flexibilityonly training for patients with fibromyalgia in the same Cochrane Review. Additionally, a meta-analysis that examined 33 trials in which physical therapy and exercise were used as treatment for fibromyalgia indicated a moderate effect on pain [23].

- A systematic review including 10 randomized controlled trials and a total of 967 patients concluded that strong evidence supported shortterm effectiveness of yoga for low back pain patients and moderate evidence for the long-term effectiveness, Class I [25].

- In a randomized trial of 313 patients with chronic low back pain, Tilbrook et al. found that patients offered yoga $(n=156)$ versus usual care $(n=157)$ had better back function (measured with the RolandMorris Disability Questionnaire), and higher pain self-efficiency scores at 3, 6, and 12 months, Class I [27].

- In another randomized controlled trial of 228 adults with chronic low back pain, Sherman et al. found that yoga was superior to a selfcare book: at 12 weeks, mean difference for function, -2.5 (95\% CI, 3.7 to -1.3$), \mathrm{P}<0.001$; and at 26 weeks, mean difference, -1.8 (95\% 
CI, -3.1 to -0.5$) ; \mathrm{P}<.001$, but not different from conventional stretching at any time [26].

- In a systematic review of yoga for rheumatic diseases, Cramer et al. found two randomized controlled trials pertaining to yoga for fibromyalgia. Based on these data, only a weak recommendation could be made, Class I [28].

\section{Other treatments}

Clinical trials have investigated acupuncture, Cognitive Behavioral Therapy (CBT), and massage as effective treatment options for chronic pain in general populations, with limited evidence in populations with addiction or opioid dependence. Mindfulness and qigong have not been shown to be effective for pain conditions. CBT, while effective for pain, has not been shown to be effective for addiction. It is not clear how it would work in populations with opioid dependence and pain.

\section{Acupuncture for chronic pain}

- Acupuncture uses thin needles inserted into specific points on the body, and has been used in China for centuries to treat many disorders. A more modern type of acupuncture, transcutaneous electric acupoint stimulation (TEAS), uses electrodes placed on the skin to apply electrical stimulation at acupoints.

- Acupuncture has been shown to be effective in reducing pain in patients with chronic pain conditions. A Cochrane review of 9 randomized controlled trials indicates low to moderate quality evidence supports the use of acupuncture to improve pain and stiffness in patients with fibromyalgia, Class I [66].

- In a meta-analysis including 29 RCTs and data for 17, 922 patients, Vickers et al. found that acupuncture improved pain in back and neck pain, chronic headache, and shoulder pain $(\mathrm{P}<0.001)$, Class I [67].

- Cherkin et al. performed a four-arm randomized trial of 638 patients with chronic low back pain and determined that improvements in back-related dysfunction (measured with the Roland-Morris Disability Questionnaire score) were greater in patients receiving individualized, standardized, or simulated acupuncture as compared with controls, Class I [68•]. These improvements were still present at one year.

- Acupuncture may also play a role in decreasing opioid use in chronic pain patients. In a small randomized controlled trial of 35 chronic pain patients receiving opioids for pain, short-term reduction in opioid-like medications (codeine, methadone, oxycodone, morphine and tramadol) was found in those who received acupuncture (39 \% versus $25 \%$ reduction in opioid use), Class II [69]. However, the reduced consumption of opioids did not last beyond eight weeks of treatment. A Cochrane review including this study stated that no 
conclusions could be made about the efficacy of the acupuncture treatment for reducing opioid use in chronic non-cancer pain patients, Class I [70].

\section{Cognitive behavioral therapy (CBT)}

- In a Cochrane review of patients with chronic pain, CBT was found to have small to moderate effects on disability, pain, mood, and catastrophizing when compared with treatment as usual, but only mild improvements in disability and catastrophizing when compared with active controls, Class I [10].

- In a systematic review and meta-analysis including 14 randomized trials and 910 patients with fibromyalgia, CBT was found to reduce depressed mood after treatment (SMD -0.24, $95 \%$ CI -0.40, -0.08; $\mathrm{P}=0.004$ ), and the number of physician visits (SMD -1.57, $95 \% \mathrm{CI}$ $2.00,-1.14 ; \mathrm{P}<0.001)$, but no effect was found on pain, fatigue, sleep, and health-related quality of life, Class I [71].

- In a trial of 701 adults, patients with chronic low back pain were randomized to six sessions of group CBT $(n=468)$ or control $(n=233)$. The outcomes of a Roland Morris disability questionnaire (difference between groups 1.3 points, $0.56-2.06, \mathrm{p}=0.0008$ ) and modified Von Korff disability (difference $8.4 \%, 4.47-12.32, \mathrm{p}<0.0001$ ) and pain scores (difference $7.0 \%, 3.12-10.81, \mathrm{p}<0.0001$ ) at 12 months showed continued improvement on chronic low back pain in patients who received the intervention compared with controls [9].

- In a Cochrane review of any psychosocial intervention plus pharmacological standard versus pharmacological standard treatment of opioid dependence, 34 randomized trials including 3,777 patients were included, Class I [11]. The authors concluded that adding psychosocial support does not change retention in treatment or opiate use during treatment.

- In a trial of 141 opioid dependent patients receiving buprenorphine/ naloxone in a primary care setting, patients were randomized to physician management or physician management and CBT. No difference in effectiveness for addiction was found between the two groups, Class II [12].

- In Cochrane review of psychosocial treatment only for opioid abuse and dependence, five randomized trials including 389 patients were analyzed. Mayet et al. found that psychosocial treatments are not currently proved to be effective alone and are not superior to any other type of treatment, Class I [13].

\section{Mindfulness}

- In a trial of 99 patients with chronic pain, patients were randomized to receive a mindfulness-based stress reduction 
(MBSR) program $(\mathrm{n}=51)$ or a multidisciplinary intervention $(\mathrm{n}=48)$, and no significant difference in pain intensity or painrelated distress was found between the two groups, Class II [15].

- In a three-armed randomized controlled trial of 177 female patients with fibromyalgia, patients were randomized to MBSR $(n=53)$, active control $(n=56)$, or a wait list $(n=59)$. No significant differences between groups in health-related quality of life (HRQoL) was found $(\mathrm{p}=0.004)$, Class II [14]. Post-hoc analysis showed that patients receiving MBSR had the greatest pre-to-post improvements in HRQoL $(\mathrm{p}=0.02)$.

\section{Qigong}

- Qigong is a form of Chinese medicine that includes deep breathing exercises and meditation, and has been investigated as a treatment for pain due to fibromyalgia. In a systematic review of 7 articles and 395 fibromyalgia patients, Lauche et al. found low-quality evidence to support the use of qigong to improve pain, quality of life, and sleep. No evidence was found for superiority of qigong over usual care of patients with fibromyalgia, Class I [72].

\section{Massage}

- In a systematic review, Kumar et al. concluded that massage may have some increased benefit for patients with chronic pain compared with relaxation, but no statement could be made about spinal manipulation, Class I [73].

- In a trial of 401 patients randomized to structural massage $(\mathrm{n}=$ 132), relaxation massage $(n=136)$ or usual care $(n=133)$, the adjusted Roland Disability Questionnaire score was lower in both the relaxation and structural massage groups after 10 weeks, Class II [74].

Multidisciplinary treatment for pain conditions has been shown in individual trials, meta-analyses and systematic reviews to be more effective than control conditions [75]. Inpatient treatment programs tend to be more intense that outpatient but do not have strong advantage over outpatient treatment when accounting for intensity. In particular, chronic back pain benefits from multidisciplinary treatment. A Cochrane review of multidisciplinary treatment for fibromyalgia showed mixed results without evidence of efficacy in low quality studies [76]. Behavioral treatment and stress reduction as well as 
physical training appear to be beneficial aspects of multidisciplinary

treatment, Class II [76].

\section{Compliance with Ethics Guidelines}

\section{Conflict of interest}

Jane Liebschutz declares that she has no conflict of interest.

Allison Lange declares that she has no conflict of interest.

Donna Beers declares that she has no conflict of interest.

Human and Animal Rights and Informed Consent

This article does not contain any studies with human or animal subjects performed by any of the authors.

\section{References and Recommended Reading}

Papers of particular interest, published recently, have been highlighted as:

- Of importance

1. Stewart WF, Ricci JA, Chee E, Morganstein D, Lipton $\mathrm{R}$. Lost productive time and cost due to common pain conditions in the US workforce. Jama. 2003;290(18):2443-54.

2. Compton P, Charuvastra VC, Ling W. Pain intolerance in opioid-maintained former opiate addicts: effect of long-acting maintenance agent. Drug Alcohol Depend. 2001;63(2):139-46.

3. Pud D, Cohen D, Lawental E, Eisenberg E. Opioids and abnormal pain perception: New evidence from a study of chronic opioid addicts and healthy subjects. Drug Alcohol Depend. 2006;82(3):218-23.

4. Barry DT, Beitel M, Garnet B, Joshi D, Rosenblum A, Schottenfeld RS. Relations among psychopathology, substance use, and physical pain experiences in methadone-maintained patients. J Clin Psychiatry. 2009;70(9):1213-8.

5. Rosenblum A, Joseph H, Fong C, Kipnis S, Cleland C, Portenoy RK. Prevalence and characteristics of chronic pain among chemically dependent patients in methadone maintenance and residential treatment facilities. JAMA. 2003;289(18):2370-8.

6. Tsui JI, Herman DS, Kettavong M, Alford D, Anderson BJ, Stein MD. Physician introduction to opioids for pain among patients with opioid dependence and depressive symptoms. J Subst Abuse Treat. 2010;39(4):378-83.

7. Ang DC, Bair MJ, Damush TM, Wu J, Tu W, Kroenke K. Predictors of pain outcomes in patients with chronic musculoskeletal pain co-morbid with de- pression: results from a randomized controlled trial. Pain Med. 2010;11(4):482-91.

8. Tsui JI, Cheng DM, Coleman SM, Blokhina E, Bridden C, Krupitsky E, et al. Pain is associated with heroin use over time in HIV-infected Russian drinkers. Addiction. 2013;108(10):1779-87.

9. Lamb SE, Hansen Z, Lall R, Castelnuovo E, Withers EJ, Nichols V, et al. Group cognitive behavioural treatment for low-back pain in primary care: a randomised controlled trial and cost-effectiveness analysis. Lancet. 2010;375(9718):916-23.

10. Williams AC, Eccleston C, Morley S. Psychological therapies for the management of chronic pain (excluding headache) in adults. Cochrane Database Syst Rev. 2012;14(11).

11. Amato L, Minozzi S, Davoli M, Vecchi S. Psychosocial combined with agonist maintenance treatments versus agonist maintenance treatments alone for treatment of opioid dependence. Cochrane Database Syst Rev. 2011;5(10).

12. Fiellin DA, Barry DT, Sullivan LE, Cutter CJ, Moore BA, O'Connor PG, et al. A randomized trial of cognitive behavioral therapy in primary care-based buprenorphine. Am J Med. 2013;126(1):005.

13. Mayet S, Farrell M, Ferri M, Amato L, Davoli M. Psychosocial treatment for opiate abuse and dependence. Cochrane Database Syst Rev. 2005;25(1).

14. Schmidt S, Grossman P, Schwarzer B, Jena S, Naumann J, Walach $H$. Treating fibromyalgia with mindfulness-based stress reduction: results from a 3- 
armed randomized controlled trial. Pain. 2011;152(2):361-9.

15. Wong SY, Chan FW, Wong RL, Chu MC, Kitty Lam YY, Mercer SW, et al. Comparing the effectiveness of mindfulness-based stress reduction and multidisciplinary intervention programs for chronic pain: a randomized comparative trial. Clin J Pain. 2011;27(8):724-34.

16. Herring MP, O'Connor PJ, Dishman RK. The effect of exercise training on anxiety symptoms among patients: a systematic review. Arch Intern Med. 2010;170(4):321-31.

17. Martin CK, Church TS, Thompson AM, Earnest CP, Blair SN. Exercise dose and quality of life: a randomized controlled trial. Arch Intern Med. 2009;169(3):269-78.

18. Hankinson AL, Daviglus ML, Bouchard C, Carnethon M, Lewis CE, Schreiner PJ, et al. Maintaining a high physical activity level over 20 years and weight gain. Jama. 2010;304(23):2603-10.

19. Rainville J, Hartigan C, Martinez E, Limke J, Jouve C, Finno M. Exercise as a treatment for chronic low back pain. Spine J. 2004;4(1):106-15.

20. Hayden JA, van Tulder MW, Malmivaara A, Koes BW. Exercise therapy for treatment of non-specific low back pain. Cochrane Database Syst Rev. 2005;20(3).

21. Hayden JA, van Tulder MW, Tomlinson G. Systematic review: strategies for using exercise therapy to improve outcomes in chronic low back pain. Ann Intern Med. 2005;142(9):776-85.

22. Busch AJ, Barber KA, Overend TJ, Peloso PM, Schachter CL. Exercise for treating fibromyalgia syndrome. Cochrane Database Syst Rev. 2007;17(4).

23. Nuesch E, Hauser W, Bernardy K, Barth J, Juni P. Comparative efficacy of pharmacological and nonpharmacological interventions in fibromyalgia syndrome: network meta-analysis. Ann Rheum Dis. 2013;72(6):955-62.

24. Hauser W, Thieme K, Turk DC. Guidelines on the management of fibromyalgia syndrome - a systematic review. Eur J Pain. 2010;14(1):5-10.

25. Cramer H, Lauche R, Haller H, Dobos G. A systematic review and meta-analysis of yoga for low back pain. Clin J Pain. 2013;29(5):450-60.

26. Sherman KJ, Cherkin DC, Wellman RD, Cook AJ, Hawkes RJ, Delaney K, et al. A randomized trial comparing yoga, stretching, and a self-care book for chronic low back pain. Arch Intern Med. 2011;171(22):2019-26.

27. Tilbrook HE, Cox H, Hewitt CE, Kang'ombe AR, Chuang LH, Jayakody S, et al. Yoga for chronic low back pain: a randomized trial. Ann Intern Med. 2011;155(9):569-78.

28. Cramer H, Lauche R, Langhorst J, Dobos G. Yoga for rheumatic diseases: a systematic review. Rheumatology. 2013;52(11):2025-30.
29. Senna MK, Sallam RA, Ashour HS, Elarman M. Effect of weight reduction on the quality of life in obese patients with fibromyalgia syndrome: a randomized controlled trial. Clin Rheumatol. 2012;31(11):1591-7.

30. Neumann AM, Blondell RD, Jaanimagi U, Giambrone AK, Homish GG, Lozano JR, et al. A preliminary study comparing methadone and buprenorphine in patients with chronic pain and coexistent opioid addiction. J Addict Dis. 2013;32(1):68-78.

This small randomized trial compared methadone and buprenorphine as treatments for chronic pain in patients with opioid dependence.

31. Christensen R, Bartels EM, Astrup A, Bliddal H. Effect of weight reduction in obese patients diagnosed with knee osteoarthritis: a systematic review and metaanalysis. Ann Rheum Dis. 2007;66(4):433-9.

32. Messier SP, Loeser RF, Miller GD, Morgan TM, Rejeski WJ, Sevick MA, et al. Exercise and dietary weight loss in overweight and obese older adults with knee osteoarthritis: the Arthritis, Diet, and Activity Promotion Trial. Arthritis Rheum. 2004;50(5):1501-10.

33. Roddy E, Zhang W, Doherty M. Aerobic walking or strengthening exercise for osteoarthritis of the knee? A systematic review. Ann Rheum Dis. 2005;64(4):544-8.

34. Nicholas MK, Asghari A, Blyth FM, Wood BM, Murray $\mathrm{R}$, McCabe $\mathrm{R}$, et al. Self-management intervention for chronic pain in older adults: a randomised controlled trial. Pain. 2013;154(6):824-35.

35. Gustavsson C, Denison E, von Koch L. Self-management of persistent neck pain: two-year follow-up of a randomized controlled trial of a multicomponent group intervention in primary health care. Spine (Phila Pa 1976). 2011;36(25):2105-15.

36. Turk DC, Wilson HD, Cahana A. Treatment of chronic non-cancer pain. Lancet. 2011;377(9784):2226-35.

37. Gilron I, Bailey JM, Tu D, Holden RR, Weaver DF, Houlden RL. Morphine, Gabapentin, or their combination for neuropathic pain. New England J Med. 2005;352(13):1324-34. doi:10.1056/ NEJMoa042580.

38. Organization WH. Cancer Pain Relief with a guide to opioid availability Geneva World Health Organization 1996

39. Towheed TE, Maxwell L, Judd MG, Catton M, Hochberg MC, Wells G. Acetaminophen for osteoarthritis. Cochrane Database Syst Rev. 2006;25(1).

40. Kroenke K, Krebs EE, Bair MJ. Pharmacotherapy of chronic pain: a synthesis of recommendations from systematic reviews. Gen Hosp Psychiatry. 2009;31(3):206-19.

41. Roelofs PD, Deyo RA, Koes BW, Scholten RJ, van Tulder MW. Nonsteroidal anti-inflammatory drugs 
for low back pain: an updated Cochrane review. Spine (Phila Pa 1976). 2008;33(16):1766-74.

42. Zerbini C, Ozturk ZE, Grifka J, Maini M, Nilganuwong S, Morales R, et al. Efficacy of etoricoxib $60 \mathrm{mg} /$ day and diclofenac $150 \mathrm{mg} /$ day in reduction of pain and disability in patients with chronic low back pain: results of a 4 -week, multinational, randomized, double-blind study. Curr Med Res Opin. 2005;21(12):2037-49.

43. Chung JW, Zeng Y, Wong TK. Drug therapy for the treatment of chronic nonspecific low back pain: systematic review and meta-analysis. Pain Physician. 2013;16(6):E685-704.

44. Malskat WS, Knulst AC, Bruijnzeel-Koomen CA, Rockmann H. Tolerance to alternative cyclooxygenase-2 inhibitors in nonsteroidal anti-inflammatory drug hypersensitive patients. Clin Transl Allergy. 2013;3(1):2045-7022.

45. Tofferi JK, Jackson JL, O'Malley PG. Treatment of fibromyalgia with cyclobenzaprine: A meta-analysis. Arthritis Rheum. 2004;51(1):9-13.

46. Moldofsky H, Harris HW, Archambault WT, Kwong T, Lederman S. Effects of bedtime very low dose cyclobenzaprine on symptoms and sleep physiology in patients with fibromyalgia syndrome: a double-blind randomized placebo-controlled study. J Rheumatol. 2011;38(12):2653-63.

47. Spence MM, Shin PJ, Lee EA, Gibbs NE. Risk of injury associated with skeletal muscle relaxant use in older adults. Ann Pharmacother. 2013;47(7-8):993-8.

48. Wiffen PJ, Derry S, Moore RA, Aldington D, Cole P, Rice AS et al. Antiepileptic drugs for neuropathic pain and fibromyalgia - an overview of Cochrane reviews. Cochrane Database Syst Rev. 2013;11(11).

49. Argoff CE, Backonja MM, Belgrade MJ, Bennett GJ, Clark MR, Cole BE, et al. Consensus guidelines: treatment planning and options. Diabetic peripheral neuropathic pain. Mayo Clin Proc. 2006;81(4 Suppl):S12-25.

50. Dworkin RH, O'Connor AB, Backonja M, Farrar JT, Finnerup NB, Jensen TS, et al. Pharmacologic management of neuropathic pain: evidence-based recommendations. Pain. 2007;132(3):237-51.

51. Hauser W, Bernardy K, Uceyler N, Sommer C. Treatment of fibromyalgia syndrome with antidepressants: a meta-analysis. Jama. 2009;301(2):198-209.

52. Moore RA, Derry S, Aldington D, Cole P, Wiffen PJ. Amitriptyline for neuropathic pain and fibromyalgia in adults. Cochrane Database Syst Rev. 2012;12(12).

53. Kroenke K, Bair MJ, Damush TM, Wu J, Hoke S, Sutherland J, et al. Optimized antidepressant therapy and pain self-management in primary care patients with depression and musculoskeletal pain: a randomized controlled trial. Jama. 2009;301(20):2099110.
54. Lunn MP, Hughes RA, Wiffen PJ. Duloxetine for treating painful neuropathy, chronic pain or fibromyalgia. Cochrane Database Syst Rev. 2014;3(1).

55. Zin CS, Nissen LM, Smith MT, O'Callaghan JP, Moore BJ. An update on the pharmacological management of post-herpetic neuralgia and painful diabetic neuropathy. CNS Drugs. 2008;22(5):417-42.

56. Frakes EP, Risser RC, Ball TD, Hochberg MC, Wohlreich MM. Duloxetine added to oral nonsteroidal anti-inflammatory drugs for treatment of knee pain due to osteoarthritis: results of a randomized, double-blind, placebo-controlled trial. Curr Med Res Opin. 2011;27(12):2361-72.

57. Abou-Raya S, Abou-Raya A, Helmii M. Duloxetine for the management of pain in older adults with knee osteoarthritis: randomised placebo-controlled trial. Age Ageing. 2012;41(5):646-52.

58. Noble M, Treadwell JR, Tregear SJ, Coates VH, Wiffen PJ, Akafomo C et al. Long-term opioid management for chronic noncancer pain. Cochrane Database Syst Rev. 2010;20(1).

59. Joseph H, Stancliff S, Langrod J. Methadone maintenance treatment (MMT): a review of historical and clinical issues. Mt Sinai J Med. 2000;67(5-6):34764.

60. Corkery JM, Schifano F, Ghodse AH, Oyefeso A. The effects of methadone and its role in fatalities. Hum Psychopharmacol. 2004;19(8):565-76.

61. Khaliq W, Alam S, Puri N. Topical lidocaine for the treatment of postherpetic neuralgia. Cochrane Database Syst Rev. 2007;18(2).

62. Argoff CE. Topical analgesics in the management of acute and chronic pain. Mayo Clin Proc. 2013;88(2):195-205.

63. Mason L, Moore RA, Derry S, Edwards JE, McQuay HJ. Systematic review of topical capsaicin for the treatment of chronic pain. Bmj. 2004;328(7446):19.

64. Haroutiunian S, Drennan DA, Lipman AG. Topical NSAID therapy for musculoskeletal pain. Pain Med. 2010;11(4):535-49.

65. Derry S, Moore RA, Rabbie R. Topical NSAIDs for chronic musculoskeletal pain in adults. Cochrane Database Syst Rev. 2012;12(9).

66. Deare JC, Zheng Z, Xue CC, Liu JP, Shang J, Scott SW et al. Acupuncture for treating fibromyalgia. Cochrane Database Syst Rev. 2013;31(5).

67. Vickers AJ, Cronin AM, Maschino AC, Lewith G, MacPherson H, Foster NE, et al. Acupuncture for chronic pain: individual patient data meta-analysis. Arch Intern Med. 2012;172(19):1444-53.

68. Cherkin DC, Sherman KJ, Avins AL, Erro JH, Ichikawa L, Barlow WE, et al. A randomized trial comparing acupuncture, simulated acupuncture, and usual care for chronic low back pain. Arch Intern Med.

2009;169(9):858-66. 
This randomized trial reports that patients with chronic back pain who received acupuncture had greater improvements in back-related dysfunction, and that these improvements were present one year later.

69. Zheng Z, Guo RJ, Helme RD, Muir A, Da Costa C, Xue CC. The effect of electroacupuncture on opioidlike medication consumption by chronic pain patients: a pilot randomized controlled clinical trial. Eur J Pain. 2008;12(5):671-6.

70. Windmill J, Fisher E, Eccleston C, Derry S, Stannard $\mathrm{C}$, Knaggs $\mathrm{R}$ et al. Interventions for the reduction of prescribed opioid use in chronic non-cancer pain. Cochrane Database Syst Rev. 2013;1(9).

71. Bernardy K, Fuber N, Kollner V, Hauser W. Efficacy of cognitive-behavioral therapies in fibromyalgia syndrome - a systematic review and metaanalysis of randomized controlled trials. J Rheumatol. 2010;37(10):1991-2005.

72. Lauche R, Cramer H, Hauser W, Dobos G, Langhorst $\mathrm{J}$. A systematic review and meta-analysis of qigong for the fibromyalgia syndrome. Evid Based Complement Alternat Med. 2013;635182(10):31.

73. Kumar S, Beaton K, Hughes T. The effectiveness of massage therapy for the treatment of nonspecific low back pain: a systematic review of systematic reviews. Int J Gen Med. 2013;6:733-41. eCollection 2013.

74. Cherkin DC, Sherman KJ, Kahn J, Wellman R, Cook AJ, Johnson E, et al. A comparison of the effects of 2 types of massage and usual care on chronic low back pain: a randomized, controlled trial. Ann Intern Med. 2011;155(1):1-9.

75. Scascighini L, Toma V, Dober-Spielmann S, Sprott H. Multidisciplinary treatment for chronic pain: a systematic review of interventions and outcomes. Rheumatology. 2008;47(5):670-8.

76. Karjalainen K, Malmivaara A, van Tulder M, Roine R, Jauhiainen M, Hurri $H$ et al. Multidisciplinary rehabilitation for fibromyalgia and musculoskeletal pain in working age adults. Cochrane Database Syst Rev. 2000;2. 